\title{
Airway remodelling and its relationship to inflammation in cystic fibrosis
}

\author{
Nicolas Regamey, ${ }^{1,2,3}$ Peter K Jeffery, ${ }^{2}$ Eric W F W Alton, ${ }^{2}$ Andrew Bush, ${ }^{1}$ \\ Jane C Davies ${ }^{1,2}$
}

1 Department of Paediatric Respiratory Medicine, Royal Brompton Hospital, London, UK 2Department of Gene Therapy, National Heart and Lung Institute, Imperial College London, UK

${ }^{3}$ Division of Paediatric Respiratory Medicine, University Children's Hospital, Bern, Switzerland

\section{Correspondence to} Nicolas Regamey, Division of Paediatric Respiratory Medicine, University Children's Hospital,

3010 Bern, Switzerland: nicolas.regamey@insel.ch

Received 28 December 2009 Accepted 9 June 2010 Published Online First 1 October 2010

\section{ABSTRACT}

Pulmonary disease is the most important cause of morbidity and mortality in cystic fibrosis (CF). Most patients with CF die from respiratory failure with extensive airway destruction. Airway remodelling, defined as structural airway wall changes, begins early in life in CF but the sequence of remodelling events in the disease process is poorly understood. Airway remodelling in CF has traditionally been thought to be solely the consequence of repeated cycles of inflammation and infection. However, new evidence obtained from developmental, physiological and histopathological studies suggests that there might instead be multiple mechanisms leading to airway remodelling in CF including (1) changes related to infection and inflammation; (2) changes specific to CF as a result of CF transmembrane conductance regulator (CFTR) dysfunction in the airway wall, independent of infection and inflammation; and (3) protective responses to (1) and/or (2). Recent advances in bronchoscopic techniques have allowed airway mucosal (endobronchial) biopsies to be taken in children and even infants. Endobronchial biopsy studies may provide insight into the role and relative contribution of the different mechanisms of airway remodelling in CF, with the main limitation that they assess only changes in proximal large airways and not in peripheral small airways from where CF disease is thought to originate. Findings from biopsy studies could encourage the development of novel therapeutic strategies targeting structural changes in addition to infection and inflammation.

\section{INTRODUCTION}

Pulmonary disease is the most important cause of morbidity and mortality in cystic fibrosis (CF). It is characterised by extensive structural airway changes including bronchiectasis, bronchiectatic pus-filled cysts, mucoid impaction, atelectasis, fibrosis and vascular changes. These structural changes in the airway wall are referred to as remodelling which, in this context, has been defined as an alteration in size, mass or number of tissue structural components inappropriate to the maintenance of normal function. ${ }^{1}$ Airway remodelling may already be present in children with CF and, in more than $90 \%$ of patients with CF, ultimately leads to death from respiratory failure. ${ }^{2-4}$

To date, most work on the pathology of the airway wall in CF has involved the study of lungs taken at autopsy or removed prior to transplantation where there is advanced end-stage disease. Thus, little is known about disease pathogenesis in the airway during the early stages of CF. In this paper we review new evidence obtained from developmental, physiological and histopathological studies which provides information concerning the extent and development of airway remodelling in the early stages of CF and consider the implication of early structural changes in the CF lung in relation to the potential development of novel therapeutic strategies. We largely discuss human studies; relevant mouse models have recently been reviewed. 56

\section{EARLY STRUCTURAL CHANGES TO THE CF AIRWAYS}

Autopsy studies performed more than two decades ago showed changes including squamous metaplasia, submucosal mucous gland enlargement and bronchiectasis in infants and young children with $\mathrm{CF}^{2}{ }^{3}$ However, the overall health of today's children with CF is much better and pulmonary health and survival of patients in successive birth cohorts have continuously improved. ${ }^{7}$ The histopathological changes observed in autopsy studies 20 or 30 years ago may not therefore reflect what is actually happening in the lungs of the children with CF we care for now.

Despite improved pulmonary health, airway disease in CF is present early, even in asymptomatic infants. Bronchoalveolar lavage (BAL) shows the presence of both infection and inflammation in infants with CF as young as a few weeks of age. ${ }^{8}$ CT scans also demonstrate the presence of remodelling in infants with $\mathrm{CF}^{9-11}$ These studies indicate that remodelling occurs in the first months of life and includes thickened airway walls, narrowed airway lumens, air trapping and bronchiectasis. Lung function has also been shown to be diminished in infants with CF. ${ }^{12}{ }^{13}$ One study reported that lung function (measured by the raised volume rapid thoracoabdominal compression technique) was preserved during the first 6 months of life, and proposed that this period may represent a 'window of opportunity' for therapeutic interventions. ${ }^{13}$ However, the number of subjects studied at this age was small.

Thus, structural changes to the airway wall in CF appear early in life. However, the sequence of remodelling events and their relationship to infection and inflammation remains unclear. Furthermore, the degree of reversibility, if any, of these early changes has not been determined.

\section{SEOUENCE OF REMODELLING EVENTS IN CF Lessons learned from asthma}

Airway remodelling in CF is traditionally thought to be solely the consequence of repeated cycles of inflammation and infection (figure 1). In asthma, 
Figure 1 (A) Traditional view of the sequence of events leading to airway remodelling in cystic fibrosis and $(B)$ the model proposed by the authors. CFTR, cystic fibrosis transmembrane conductance regulator; RBM, reticular basement membrane.
A

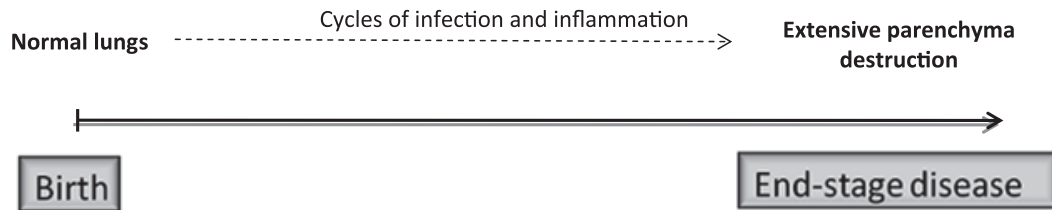

B

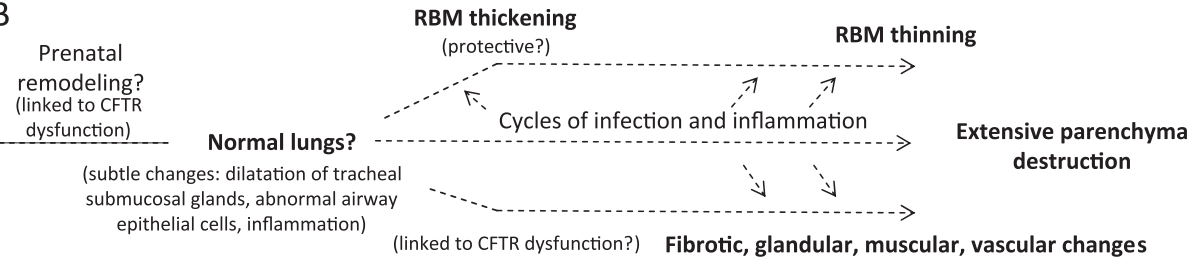

Birth 'window of opportunity' (6 months?) a similar paradigm (ie, that chronic inflammation and repeated cycles of repair lead eventually to structural alteration of the airway wall) has recently been challenged.

Studies of endobronchial biopsies in asthma have shown that thickening of the reticular basement membrane (RBM) is already present in young wheezy children and that it is of the same magnitude as that seen in adults. ${ }^{14}$ Moreover, they have demonstrated that RBM thickening in children is not related to the duration of asthma, to treatment or to any inflammatory marker investigated. Furthermore, they have shown that, while there is no evidence of either eosinophilic inflammation or airway remodelling in infants with wheeze and reversible airflow obstruction at a median age of 1 year, both are present in preschool children with wheeze at a median age of 3 years. ${ }^{15}{ }^{16}$ These findings suggest that inflammation and remodelling in asthma develop early in life and in parallel, not sequentially. This is supported by recent evidence from a novel neonatal mouse model of allergic airways disease which has shown that bronchial responsiveness, eosinophilic inflammation and remodelling occur in parallel during sequential airborne house dust mite sensitisation. ${ }^{17}$

\section{Endobronchial biopsy as a tool to study airway remodelling early in life in CF}

There is a paucity of data that shed light on the sequence of airway remodelling events in CF. In contrast to asthma where endobronchial biopsy has allowed detailed investigation of both airway remodelling and inflammation in the early stages, few groups have yet included endobronchial biopsy in their investigations of remodelling in CF (table 1).

We have demonstrated the safety of endobronchial biopsy in infants and small children, including those with $\mathrm{CF}^{26}$ The additional biopsy procedure takes only a few minutes, which we consider represents an acceptable increase in the duration of fibreoptic bronchoscopy for the purpose of research. ${ }^{27}$ In addition, we have reported that biopsy size and quality are adequate for the study of airway remodelling in children and infants with $\mathrm{CF}^{28}$

There are, however, clearly limitations to this approach as the sample is only from (1) relatively proximal large airways rather than the distal small airways from where the earliest abnormal physiological signal originates ${ }^{29}$; (2) the airway mucosa of bronchial bifurcations (carinae) rather than the full thickness of the airway wall; and (3) an extremely small portion of the airway tree. The last-mentioned limitation is important because of intrasubject and interbiopsy variability and can be mitigated in part by sampling at least two sites. ${ }^{28}$

Provided studies are performed according to ethical guidelines and by experienced staff as part of focused hypothesisdriven research and processed adequately, biopsy studies may yield valuable new information about the pathogenesis of airway remodelling in CF children with early-stage lung disease

Table 1 Studies that have used endobronchial biopsy to investigate airway remodelling in cystic fibrosis (CF)

\begin{tabular}{|c|c|c|c|c|}
\hline Author & Year & CF subjects & Structures studied & Main findings \\
\hline Gilljam $^{18}$ & 1987 & Adults $(n=7)$ & Epithelium & Loss of microvilli, otherwise no abnormalities of the epithelium \\
\hline Durieu $^{19}$ & 1998 & Children and adults, age $10-30$ years $(n=6)$ & RBM, subepithelium & $\begin{array}{l}\text { Thinning of the basal lamina, subepithelial fibrosis, degradation } \\
\text { of the extracellular matrix }\end{array}$ \\
\hline Wojnarowski ${ }^{20}$ & 1999 & Children, age $6-17$ years $(n=16)$ & Epithelium, subepithelium & $\begin{array}{l}\text { Lymphocytic infiltrate in stable disease, neutrophilic infiltrate in } \\
\text { exacerbation; high expression of TGF- } \beta 1 \text { and IFN- } \gamma \text { associated } \\
\text { with mild disease }\end{array}$ \\
\hline Hauber $^{21}$ & 2004 & Adults $(n=10)$ & Epithelium & $\begin{array}{l}\text { Increased PAS staining in the epithelium; increased expression } \\
\text { of IL-9, IL-9R and hCLCA1 in mucus-producing cells }\end{array}$ \\
\hline Hays ${ }^{22}$ & 2005 & Adults $(\mathrm{n}=7)$ & Smooth muscle & Hyperplasia without hypertrophy of airway smooth muscle \\
\hline Hays $^{23}$ & 2006 & Adults $(\mathrm{n}=7)$ & Goblet cells, mucus-secreting glands & $\begin{array}{l}\text { Increased goblet cell size but normal number; hypertrophy of } \\
\text { submucosal glands, with normal proportion of mucous and } \\
\text { serous acini }\end{array}$ \\
\hline Hilliard $^{24}$ & 2007 & Children, age $0-17$ years $(n=43)$ & RBM & $\begin{array}{l}\text { RBM thickening related to TGF- } \beta 1 \text { in BAL but independent of } \\
\text { other markers of inflammation }\end{array}$ \\
\hline Regamey $^{25}$ & 2008 & Children, age $6-17$ years $(n=27)$ & Smooth muscle & $\begin{array}{l}\text { Increase in airway smooth muscle (both hyperplasia and } \\
\text { hypertrophy) }\end{array}$ \\
\hline
\end{tabular}


Figure 2 Endobronchial biopsy as a tool to study airway remodelling in cystic fibrosis (CF). Low power view of an endobronchial biopsy section obtained from a 4-year-old child with CF showing (A) smooth muscle; (B) glands; (C) epithelium. Stain: H\&E.
A

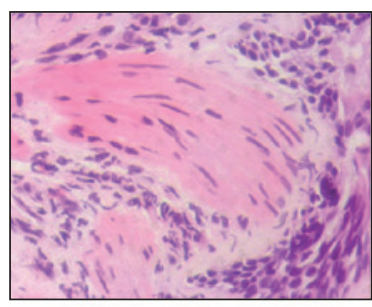

B

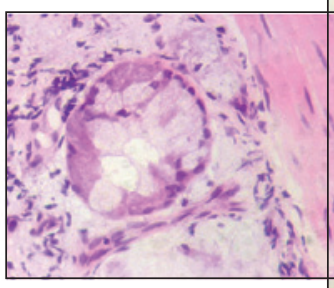

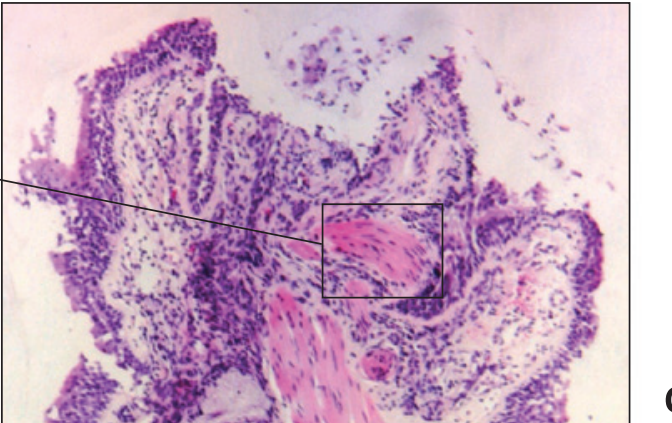

C

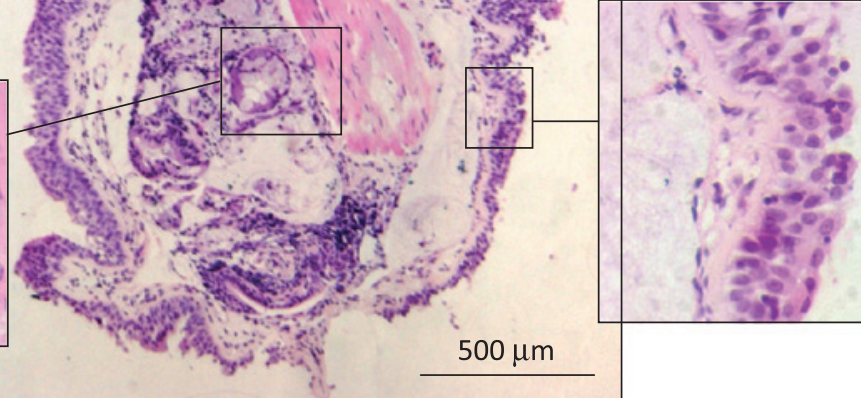

(figure 2). ${ }^{242530}$ We encourage consideration of endobronchial biopsy in children with CF, but only at the time of clinicallyindicated bronchoscopy and subject to ethics, appropriate informed consent and the caveats listed above. ${ }^{31}$

\section{RELATIONSHIP OF CF AIRWAY REMODELLING TO INFLAMMATION AND INFECTION}

As mentioned earlier, airway remodelling in CF is traditionally thought to be solely the consequence of repeated cycles of inflammation and infection. On the basis of current work we hypothesise that, in fact, there may be a number of mechanisms including (1) changes related to infection and inflammation; (2) changes specific to CF as a result of CF transmembrane conductance regulator (CFTR) dysfunction in the airway wall, independent of infection and inflammation; and (3) the result of protective responses to (1) and/or (2) (figure 1). If the hypothesis is correct, it is of more than academic importance. If remodelling in CF, eventually contributing to death, is only secondary to inflammation and/or infection, then early treatment of infection and inflammation should be an adequate therapeutic strategy alone. If there is a specific CFTR-related component, then different therapeutic strategies may be required. The following sections summarise available data on the relationships of CF airway remodelling to inflammation and infection.

\section{Developmental data}

The lungs of newborn infants with CF are thought to be essentially normal. ${ }^{32}$ However, dilatation of tracheal submucosal gland ducts, airway epithelial cells devoid of microvilli and increased levels of proinflammatory proteins have been described in CF fetuses, suggesting that subtle changes to the airways may occur prenatally. ${ }^{33-35}$ Because the fetus grows in a sterile environment, these changes are likely to be independent of infection and directly linked to CFTR dysfunction. However, if lung function is really normal very early in the life of newborn screened infants with CF (as has been suggested), then it is unlikely that antenatal remodelling is important. ${ }^{13}$

\section{Physiological data}

Physiological data (ie, respiratory function measures) have shown that the extent of airway obstruction in newly diagnosed infants with CF is unaffected by a history of lower respiratory illness, the presence of respiratory signs and symptoms, or the presence of pulmonary infection and inflammation in BAL fluid samples. ${ }^{12} 1336$ Moreover, despite treatment of infection and inflammation, there is no 'catch-up' in airway function during infancy and early childhood or into the school years. ${ }^{12} 3637$ Even in children with CF with no apparent respiratory complications, there appears to be a CF-specific airway obstruction suggestive of a CF-specific airway wall defect related to CFTR dysfunction and independent of infection and inflammation. ${ }^{12} 3637$

\section{Histopathological data}

The interpretation of several previous studies of lung tissues has been hampered by two factors. First, tissue has come either from infants who died from meconium ileus (no or minimal lung disease) or from lungs at the time of transplantation or death where there is advanced end-stage disease. Second, the few studies that have used endobronchial biopsy to study early stages of the disease have been cross-sectional with no longitudinal data on airway remodelling (table 1). Thus, associations between inflammatory and structural changes have been described, but there are no data on causal relationships. We have used control groups of children with other chronic suppurative lung diseases (non-CF bronchiectasis such as primary ciliary dyskinesia) to try to tease out CF-specific changes from those that are secondary to inflammation. ${ }^{24} 2538$

\section{Epithelium and reticular basement membrane (RBM)}

The thickness of the epithelial RBM has been studied at various stages of the disease. Studies in adults have yielded conflicting results; while some authors have reported RBM thickening, ${ }^{19} 39$ others have found that the RBM has been significantly thinner than normal. ${ }^{23}$ Repair processes (leading to RBM thickening) and neutrophil-mediated proteolytic degradation (leading to RBM thinning) have been proposed to explain these apparently opposing findings. It is also possible that reduced fibril synthesis late in the disease course may be important, but this is currently wholly speculative. In our studies we reported an increased RBM thickness in children with CF unrelated to the raised levels of inflammatory cells and proteins observed in BAL fluid but 
Figure 3 Histopathological changes in the cystic fibrosis (CF) airways. High power view of representative endobronchial biopsy sections obtained from a subject with $C F(A, C)$ and a control subject $(B, D)$. Hyperplasia and squamous metaplasia of the epithelium, reticular basement membrane (RBM) thickening and increase in airway smooth muscle (ASM) content are seen in the CF biopsies. Stain: H\&E.
A

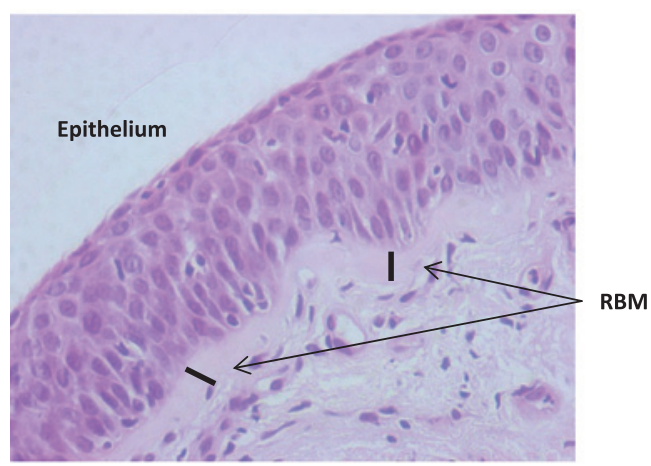

C

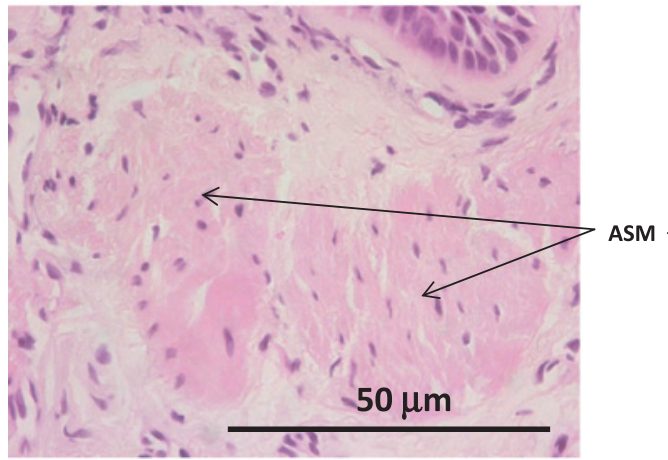

B

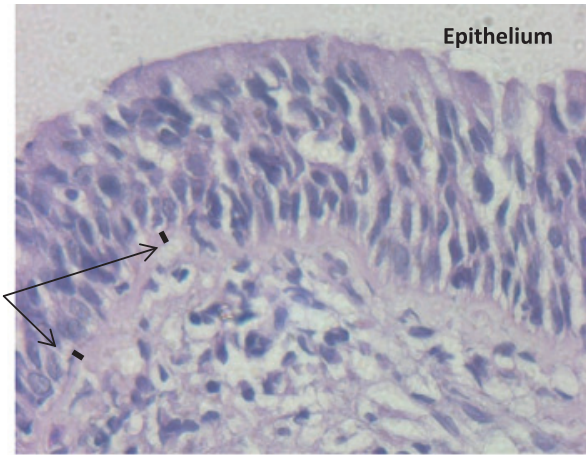

D

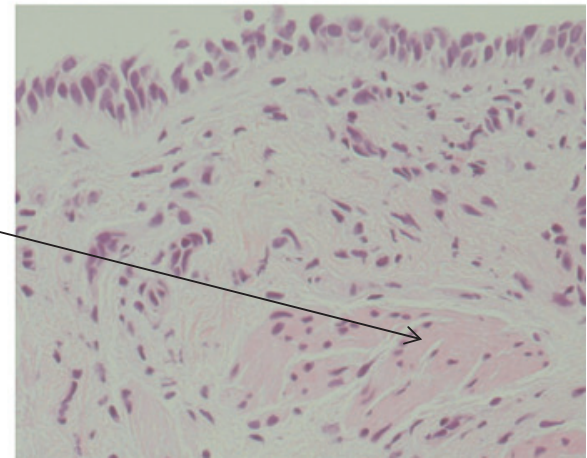

significantly related to BAL concentrations of transforming growth factor $\beta 1$ (TGF- $\beta 1$ ) (figure 3 ). ${ }^{24}$ These data indicate that this aspect of remodelling is independent of inflammation.

The airway epithelium in adults with advanced CF disease exhibits hyperplasia and squamous metaplasia, loss of ciliated epithelial cells and ultrastructural abnormalities such as disorganisation of tight junctions and compound cilia (figure 3). ${ }^{2} 18324041$ However, it is not known whether these changes are CF-specific or simply secondary to inflammation and infection. Interestingly, prenatal loss of microvilli, atrophy and metaplasia of the tracheal epithelium with an abnormal Golgi apparatus and aberrant mitochondria have also been reported in autopsy tissue from fetuses with CF, suggesting that epithelial remodelling occurs prenatally and in the absence of infection. ${ }^{33}{ }^{34}$ In support of this, a humanised nude mouse xenograft model shows delayed and abnormal epithelial regeneration in CF in the absence of bacterial infection. ${ }^{42}$ In addition, we have reported alterations in the respiratory and olfactory epithelium of CF mice, apparently unassociated with inflammation or bacterial infection. ${ }^{43}$

\section{Extracellular matrix}

There is evidence of increased airway tissue breakdown in CF. The presence of chondroitin sulfate and desmosine in sputum, raised levels of elastin and glycosaminoglycans in BAL fluid, raised levels of urinary desmosines and collagen metabolites, fragmented and exfoliated elastin in autopsy lung tissue and ultrastructural evidence of lysis of elastic and collagen fibres in endobronchial biopsies has been reported ${ }^{19} 44$ 45; these probably represent degradation of important structural components of the extracellular matrix such as elastin, collagen and glycosaminoglycans. This breakdown of the airway tissue is likely to be functionally relevant, leading to a loss of lung function and favouring the development of bronchiectasis. ${ }^{244}$ Degradation of the bronchial tissue matrix is associated with an early protease/antiprotease imbalance in CF linked to inflammation and infection. ${ }^{24} 44$
Widespread fibrotic changes causing narrowing of the small airways have been described, especially in end-stage $\mathrm{CF}^{3}{ }^{4} 19$ However, little is known about the regulation of repair processes in response to proteolytic injury, the pathogenesis of fibrotic changes and the role of growth factors and their complex regulation in $\mathrm{CF}^{46}$

\section{Glands, mucins and goblet cells}

Although dilation of tracheal submucosal gland ducts has been described in CF fetuses ${ }^{34}$ early autopsy lung specimens from infants with CF have shown that mucus-secreting submucosal glands are in general normal in both size and number, regardless of the presence of airway infection. ${ }^{32}$ However, there is an enlargement of submucosal glands in older patients. ${ }^{2}{ }^{3}$ Thus, although patients with CF seem to be born with, at most, only minor mucous cell abnormalities, major changes occur by the time of death. Recent bronchoscopic data have shown an increase in submucosal gland volume with proportionate increases in both serous and mucous cell components in adults with $\mathrm{CF}^{23}$ As submucosal glands have been found more distally (ie, in smaller airways) in CF lungs at autopsy than in controls, it seems likely that, at least in part, gland enlargement in CF results from growth (hyperplasia) of new submucosal gland cells. ${ }^{23}$ The exact mechanisms behind this gland enlargement in CF are unknown, but neutrophil-directed epithelial cell activation leading to epithelial mesenchymal transition, epithelial tubulogenesis and new gland formation has been proposed. ${ }^{23}$

Gel-forming mucins such as MUC2, MUC5AC and MUC5B are secreted by airway mucous cells. They are subject to regulation by inflammatory stimuli and contribute to airway plugging in $\mathrm{CF}^{47}$ However, studies on mucin expression and secretion in CF have yielded conflicting results. While some authors have reported increased expression or secretion of mucins in $\mathrm{CF}^{47}$ others have found the opposite. ${ }^{48}$ An increase in the volume of stored mucin in the epithelium, resulting in 
increased goblet cell size rather than number, has been shown in airway tissue obtained at transplant and in endobronchial biopsies from subjects with $\mathrm{CF}^{21} 2347$ Similarly, an increase in the volume of stored mucin in submucosal glands has been demonstrated. ${ }^{21} 23$ However, it remains controversial as to whether the increase in mucin stores represents increased mucin production and secretion that contributes to luminal plugging, ${ }^{47}$ or whether mucin secretion is slowed in CF resulting in its retention within goblet cells and glands and a lack of a protective mucous layer which would predispose the CF airway to subsequent infection. ${ }^{48}$

\section{Smooth muscle, cartilage and vessels}

There is an increase in airway smooth muscle (ASM) content in lungs (autopsy, explants or lobectomy) from adults with severe end-stage disease, as well as in biopsies obtained from CF adults with mild to moderate airway obstruction. ${ }^{22} 40$ Using endobronchial biopsies we have recently reported increases in ASM cells (both number and size) in children with CF (figure 3). ${ }^{25}$ Interestingly, these changes were also present in children with other inflammatory lung diseases such as asthma and non-CF bronchiectasis, suggesting common (not CF-specific) pathophysiological changes probably related to airway inflammation and/or infection. The cellular mechanisms leading to these structural changes are incompletely investigated, but it has been proposed that an increase in ASM could contribute to airway hyper-responsiveness. ${ }^{40} 49$

Loss of cartilage resulting in tracheomalacia and bronchomalacia and related to the severity of bronchiectasis is found in end-stage CF disease of the airways. ${ }^{40} 5051$ It is associated with chronic inflammation and infection and is preceded by destruction and fibrotic replacement of the cartilage. There is also increased bronchial blood flow and vascular remodelling in CF. The causes and mechanism(s) are unknown, but endothelial dysfunction-which is frequent in end-stage CF and involves the NF- $\kappa$ B pathway implicated in inflammation-is thought to precede the vascular changes. ${ }^{52}$

\section{Bronchial mucosal inflammation}

The most characteristic feature of pulmonary inflammation in CF is the predominance of large numbers of neutrophils in the airway lumen. ${ }^{2-4} 832$ This excess of neutrophils is considered part of a 'vicious cycle' of increased inflammation: neutrophils release an array of mediators, oxidants and proteases including neutrophil elastase which play a major role in the pathophysiology of chronic inflammation and tissue damage. The neutrophils appear to be ineffective at clearing the airway of pathogens, perhaps due in part to the cleavage of CXCR1 motifs from their surface by elastase. ${ }^{53}$ BAL studies have shown that neutrophilic inflammation occurs very early in the disease. ${ }^{8}$ Whether inflammation is a primary event linked to CFTR dysfunction or only follows infection remains unclear. ${ }^{8}$

The investigation of airway lumen events has not been paralleled by studies focused on the airway wall. Indeed, very little is known about the recruitment and accumulation of inflammatory cells in the tissues of patients with CF, and particularly that which occurs in the bronchial mucosa, one site where airway remodelling takes place. Early pathological studies have reported inflammation in the bronchial wall in children as young as a few months of age. ${ }^{2} 32$ Quantitative data of inflammatory cells in the airway wall at the time of transplantation have shown an accumulation of lymphocytes, which consisted mainly of $\mathrm{T}$ lymphocytes, especially distally where intense tissue damage is observed. ${ }^{4}{ }^{39}$ Lymphoid aggregates formed by $\mathrm{B}$ cells are also observed along the length of CF airways. In contrast, neutrophils appear to be localised mainly to the surface epithelium, suggesting a preferential migration of these cells towards the airway lumen. ${ }^{39}$ Only one study has assessed the inflammatory infiltrate occurring during earlier stages of CF lung disease; using endobronchial biopsies, Wojnarowski et al described a predominantly lymphocytic infiltrate in the airway subepithelium in children with CF with stable disease in contrast to the neutrophil-dominated infiltrate in children with CF with an acute pulmonary exacerbation. ${ }^{20}$ Thus, lymphocytes may play a role in the pathophysiology of CF lung disease, which we are currently investigating further. ${ }^{54}$

\section{IS THERE A CFTR-SPECIFIC AIRWAY DEFECT?}

Currently this is speculative. Lines of evidence that are supportive of this concept are the findings of (1) subtle prenatal changes in CF fetuses ${ }^{33-35}$; (2) airflow obstruction in children with CF who at diagnosis have no discernable respiratory complications, which persists into the school years even in the absence of respiratory complications and despite specialist treatment ${ }^{12} 133637$; and (3) histopathological changes including delayed and abnormal epithelial regeneration, epithelial thickening, increased RBM thickness and mucus cell number that appeared to be independent of infection and inflammation. ${ }^{24} 4243$

\section{FUNCTIONAL CONSEQUENCES AND REVERSIBILITY OF AIRWAY REMODELLING IN CF}

While parenchymal destruction is clearly detrimental to lung function, ${ }^{24} 44$ other changes of remodelling might in fact be protective. RBM thickening, for instance, might protect the airway by limiting the access of elastases and other proteolytic enzymes released from necrotic neutrophils in particular to the subepithelial compartment. ${ }^{55}$ It might also be protective by preventing or ameliorating airway narrowing and thus minimising air trapping and hyperinflation. As reviewed in an earlier section, both RBM thickening and thinning have been reported in CF. It has been suggested that repair processes and neutrophilmediated proteolysis may well have opposing effects on RBM thickness; thus, RBM thickening may be protective in the early stages of the disease but, subsequently, the initially protective response becomes overwhelmed and the RBM thins owing to an increased burden of elastase. ${ }^{19}$

There are no data on reversibility of airway remodelling in CF. In asthma, studies of endobronchial biopsies have demonstrated reversal upon pharmacological intervention of some components of airway remodelling such as reduction of RBM thickening or of increased airway vascularity. 5657

\section{CONCLUSIONS}

Airway remodelling in CF appears early in life and the window of opportunity for prevention of the onset of progressive airway damage that characterises CF lung disease may be short. Current strategies focus on the prevention and treatment of infection and inflammation. However, we suggest that, although important, this by itself may be insufficient. There is some evidence of CFTR-specific airway wall dysfunction and also of structural changes that may be protective; modulation of both of these may offer new therapeutic avenues.

As cross-sectional data can at best only demonstrate hypothesis-generating associations, there is a major need in the future for longitudinal studies; inclusion of endobronchial biopsy affords this possibility. We have confirmed that endobronchial biopsy is safe and feasible even in very young children 
with CF and provides us with the means to understand better the early mechanisms of airway remodelling. Although there is currently no clinical indication for performing endobronchial biopsy in children with CF, we would encourage units which routinely perform annual surveillance bronchoscopy in CF to consider performing endobronchial biopsy for research as part of this procedure so that these hypotheses can be tested.

Funding NR is the recipient of a European Respiratory Society Fellowship (Nr. 64).

Competing interests None.

Provenance and peer review Not commissioned; externally peer reviewed.

\section{REFERENCES}

1. Jeffery PK. Remodeling in asthma and chronic obstructive lung disease. Am J Respir Crit Care Med 2001;164:S28-38.

2. Bedrossian CW, Greenberg SD, Singer DB, et al. The lung in cystic fibrosis. A quantitative study including prevalence of pathologic findings among different age groups. Hum Pathol 1976;7:195-204.

3. Sobonya RE, Taussig LM. Quantitative aspects of lung pathology in cystic fibrosis. Am Rev Respir Dis 1986;134:290-5.

4. Hamutcu R, Rowland JM, Horn MV, et al. Clinical findings and lung pathology in children with cystic fibrosis. Am J Respir Crit Care Med 2002;165:1172-5.

5. Scholte BJ, Davidson DJ, Wilke M, et al. Animal models of cystic fibrosis. J Cyst Fibros 2004;3(Suppl 2):183-90.

6. Guilbault C, Saeed Z, Downey GP, et al. Cystic fibrosis mouse models. Am J Respir Cell Mol Biol 2007;36:1-7.

7. O'Sullivan BP, Freedman SD. Cystic fibrosis. Lancet 2009;373:1891-904.

8. Sly PD, Brennan S, Gangell C, et al. Lung disease at diagnosis in infants with cystic fibrosis detected by newborn screening. Am J Respir Crit Care Med 2009:180:146-52.

9. Long FR, Williams RS, Castile RG. Structural airway abnormalities in infants and young children with cystic fibrosis. J Pediatr 2004;144:154-61.

10. Martinez TM, Llapur CJ, Williams TH, et al. High-resolution computed tomography imaging of airway disease in infants with cystic fibrosis. Am J Respir Crit Care Med 2005:172:1133-8.

11. Stick SM, Brennan S, Murray C, et al. Bronchiectasis in infants and preschool children diagnosed with cystic fibrosis after newborn screening. J Pediatr 2009:155:623-8 e621.

12. Ranganathan SC, Stocks J, Dezateux C, et al. The evolution of airway function in early childhood following clinical diagnosis of cystic fibrosis. Am J Respir Crit Care Med 2004:169:928-33.

13. Linnane BM, Hall GL, Nolan G, et al. Lung function in infants with cystic fibrosis diagnosed by newborn screening. Am J Respir Crit Care Med 2008;178:1238-44.

14. Payne DN, Rogers AV, Adelroth E, et al. Early thickening of the reticular basement membrane in children with difficult asthma. Am J Respir Crit Care Med 2003:167:78-82.

15. Saglani S, Malmstrom K, Pelkonen AS, et al. Airway remodeling and inflammation in symptomatic infants with reversible airflow obstruction. Am J Respir Crit Care Med 2005:171:722-7.

16. Saglani S, Payne DN, Zhu J, et al. Early detection of airway wall remodeling and eosinophilic inflammation in preschool wheezers. Am J Respir Crit Care Med 2007:176:858-64.

17. Saglani S, Mathie SA, Gregory LG, et al. Pathophysiological features of asthma develop in parallel in house dust mite-exposed neonatal mice. Am J Respir Cell Mol Biol 2009;41:281-9.

18. Gilljam H, Motakefi AM, Robertson B, et al. Ultrastructure of the bronchial epithelium in adult patients with cystic fibrosis. Eur J Respir Dis 1987;71:187-94.

19. Durieu I, Peyrol S, Gindre D, et al. Subepithelial fibrosis and degradation of the bronchial extracellular matrix in cystic fibrosis. Am J Respir Crit Care Med 1998:158:580-8.

20. Wojnarowski C, Frischer T, Hofbauer E, et al. Cytokine expression in bronchia biopsies of cystic fibrosis patients with and without acute exacerbation. Eur Respir J 1999:14:1136-44.

21. Hauber HP, Tsicopoulos A, Wallaert B, et al. Expression of hclca1 in cystic fibrosis lungs is associated with mucus overproduction. Eur Respir $J$ 2004:23:846-50.

22. Hays SR, Ferrando RE, Carter $\mathrm{R}$, et al. Structural changes to airway smooth muscle in cystic fibrosis. Thorax 2005; 60:226-8

23. Hays SR, Fahy JV. Characterizing mucous cell remodeling in cystic fibrosis: relationship to neutrophils. Am J Respir Crit Care Med 2006;174:1018-24.

24. Hilliard TN, Regamey N, Shute JK, et al. Airway remodelling in children with cystic fibrosis. Thorax 2007;62:1074-80.

25. Regamey N, Ochs M, Hilliard TN, et al. Increased airway smooth muscle mass in children with asthma, cystic fibrosis, and non-cystic fibrosis bronchiectasis. Am J Respir Crit Care Med 2008:177:837-43.
26. Molina-Teran A, Hilliard TN, Saglani S, et al. Safety of endobronchial biopsy in children with cystic fibrosis. Pediatr Pulmonol 2006;41:1021-4.

27. Regamey N, Balfour-Lynn I, Rosenthal M, et al. Time required to obtain endobronchial biopsies in children during fiberoptic bronchoscopy. Pediatr Pulmonol 2009;44:76-9

28. Regamey N, Hilliard TN, Saglani S, et al. Quality, size, and composition of pediatric endobronchial biopsies in cystic fibrosis. Chest 2007:131:1710-17.

29. Aurora $\mathbf{P}$, Bush A, Gustafsson P, et al. Multiple-breath washout as a marker of lung disease in preschool children with cystic fibrosis. Am J Respir Crit Care Med 2005;171:249-56.

30. Jeffery $\mathbf{P}$, Holgate $\mathrm{S}$, Wenzel $\mathrm{S}$. Methods for the assessment of endobronchial biopsies in clinical research: application to studies of pathogenesis and the effects of treatment. Am J Respir Crit Care Med 2003;168:S1-17.

31. Regamey N, Hilliard TN, Saglani S, et al. Endobronchial biopsy in childhood. Chest 2008:133:312: author reply 313 .

32. Oppenheimer EH. Similarity of the tracheobronchial mucous glands and epithelium in infants with and without cystic fibrosis. Hum Pathol 1981;12:36-48.

33. Gosden CM, Gosden JR. Fetal abnormalities in cystic fibrosis suggest a deficiency in proteolysis of cholecystokinin. Lancet 1984;2:541-6.

34. Ornoy A, Arnon J, Katznelson D, et al. Pathological confirmation of cystic fibrosis in the fetus following prenatal diagnosis. Am J Med Genet 1987;28:935-47.

35. Verhaeghe C, Delbecque K, de Leval L, et al. Early inflammation in the airways of a cystic fibrosis foetus. J Cyst Fibros 2007:6:304-8.

36. Kozlowska WJ, Bush A, Wade A, et al. Lung function from infancy to the preschool years after clinical diagnosis of cystic fibrosis. Am J Respir Crit Care Med 2008:178:42-9.

37. Nielsen KG, Pressler T, Klug B, et al. Serial lung function and responsiveness in cystic fibrosis during early childhood. Am J Respir Crit Care Med 2004;169:1209-16.

38. Regamey N, Tsartsali L, Hilliard TN, et al. Airway mucosa inflammation in children with cystic fibrosis. Pediatr Pulmonol 2007;(Suppl 30):A175.

39. Hubeau C, Lorenzato M, Couetil JP, et al. Quantitative analysis of inflammatory cells infiltrating the cystic fibrosis airway mucosa. Clin Exp Immunol 2001:124:69-76.

40. Tiddens HA, Koopman LP, Lambert RK, et al. Cartilaginous airway wall dimensions and airway resistance in cystic fibrosis lungs. Eur Respir J 2000;15:735-42.

41. Godfrey RW, Severs NJ, Jeffery PK. Structural alterations of airway epithelial tigh junctions in cystic fibrosis: comparison of transplant and postmortem tissue. Am J Respir Cell Mol Biol 1993;9:148-56.

42. Haij R, Lesimple P, Nawrocki-Raby B, et al. Human airway surface epithelial regeneration is delayed and abnormal in cystic fibrosis. J Pathol 2007;211:340-50.

43. Hilliard TN, Zhu J, Farley R, et al. Nasal abnormalities in cystic fibrosis mice independent of infection and inflammation. Am J Respir Cell Mol Biol 2008;39:19-25.

44. Bruce MC, Poncz L, Klinger JD, et al. Biochemical and pathologic evidence for proteolytic destruction of lung connective tissue in cystic fibrosis. Am Rev Respir Dis 1985; 132:529-35.

45. Laguna TA, Wagner BD, Luckey HK, et al. Sputum desmosine during hospital admission for pulmonary exacerbation in cystic fibrosis. Chest 2009;136:1561-8.

46. Shute J, Marshall L, Bodey K, et al. Growth factors in cystic fibrosis - when more is not enough. Paediatr Respir Rev 2003:4:120-7.

47. Burgel PR, Montani D, Danel C, et al. A morphometric study of mucins and small airway plugging in cystic fibrosis. Thorax 2007;62:153-61.

48. Henke Mo, Renner A, Huber RM, et al. Muc5ac and muc5b mucins are decreased in cystic fibrosis airway secretions. Am J Respir Cell Mol Biol 2004;31:86-91.

49. James A, Carroll N. Airway smooth muscle in health and disease: methods of measurement and relation to function. Eur Respir $J$ 2000;15:782-9.

50. Ogrinc G, Kampalath B, Tomashefski JF Jr. Destruction and loss of bronchial cartilage in cystic fibrosis. Hum Pathol 1998;29:65-73.

51. McDermott S, Barry SC, Judge EE, et al. Tracheomalacia in adults with cystic fibrosis: determination of prevalence and severity with dynamic cine CT. Radiology 2009;252:577-86

52. Henno P, Maurey $\mathrm{C}$, Danel $\mathrm{C}$, et al. Pulmonary vascular dysfunction in end-stage cystic fibrosis: role of NF-kB and endothelin-1. Eur Respir J 2009:34:1329-37.

53. Hartl D, Latzin P, Hordijk P, et al. Cleavage of CXCR1 on neutrophils disables bacterial killing in cystic fibrosis lung disease. Nat Med 2007;13:1423-30.

54. Tan HL, Regamey N, Hilliard T, et al. Exploring the phenotype of the lymphocytic infiltrate in the CF airway: do IL-17+ cells play a role in disease pathogenesis? Pediatr Pulmonol 2009:44:A126.

55. Milanese M, Crimi E, Scordamaglia A, et al. On the functional consequences of bronchial basement membrane thickening. J Appl Physiol 2001;91:1035-40.

56. Sont JK, Willems LN, Bel EH, et al. Clinical control and histopathologic outcome of asthma when using airway hyperresponsiveness as an additional guide to long-term treatment. The Ampul Study Group. Am J Respir Crit Care Med 1999:159:1043-51

57. Chetta A, Zanini A, Foresi A, et al. Vascular component of airway remodeling in asthma is reduced by high dose of fluticasone. Am J Respir Crit Care Med 2003:167:751-7. 